\title{
PRODUÇÃO DE XILANASE POR PENICILLIUM SP. UTILIZANDO RESÍDUO AGROINDUSTRIAL EM FERMENTAÇÃO EM ESTADO SÓLIDO
}

\author{
N. A. DARONCH ${ }^{1}$, J. ZENI ${ }^{1}$, L. N. SALAZAR ${ }^{1}$, G. TONIAZZO ${ }^{1}$, R. L. CANSIAN ${ }^{1}$, N. L. \\ D. NYARI ${ }^{1}$, E. MALVESSI ${ }^{2}$
}

${ }^{1}$ Universidade Regional Integrada do Alto Uruguai e das Missões, Departamento de Engenharia de Alimentos

${ }^{2}$ Universidade de Caxias do Sul, Instituto de Biotecnologia

E-mail para contato: naionaradaronch@hotmail.com

\begin{abstract}
RESUMO - Neste trabalho objetivou-se otimizar a produção de xilanase a partir do micro-organismo Penicillium sp. em termo de concentração de esporos e umidade. Para a determinação dos valores da concentração de esporos e umidade foi realizado um planejamento fatorial completo $2^{2}$, onde a concentração de esporos variou de $4,6 \log$ a $7,4 \log$ e umidade de $34 \%$ a $76 \%$. A determinação da atividade residual foi realizada adicionando-se $0,2 \mathrm{~mL}$ de enzima a $1,8 \mathrm{~mL}$ de Xilana $1 \%(\mathrm{~m} / \mathrm{v})$ em tampão citrato de sódio $0,05 \mathrm{M} \mathrm{pH} 5,3$ segundo metodologia de Bailey et al. (1992). De acordo com os resultados obtidos noplanejamento estatístico experimental, a atividade para xilanase apresentou a maior atividade enzimática $(435,35 \mathrm{U} / \mathrm{g})$ com concentração de esporos $7 \mathrm{Log} \mathrm{e}$ umidade de $70 \%$.
\end{abstract}

\section{INTRODUÇÃO}

O principal polissacarídeo componente da hemicelulose é a xilana, o qual está presente em todas as camadas da parede celular vegetal na interface entre a celulose e a lignina. Depois da celulose, a xilana é a fonte renovável de carbono mais abundante, presente na madeira e resíduos agrícolas (ZANOELO et al., 2004)..

Na natureza, o interesse pela hidrólise da xilana se dá pela ação de várias enzimas do complexo xilanolítico, dos quais, principalmente as xilanases é que fazem parte desse complexo e são responsáveis pela hidrólise da xilana (LEE et al., 2009).

A maior aplicação industrial da xilanase, livre de celulase, está relacionada às indústrias de celulose e papel. Nesta aplicação, as xilanases podem auxiliar consideravelmente na redução da poluição ambiental, causada pela utilização do cloro como agente químico branqueador das polpas, o que resulta na formação de compostos residuais denominados organo-clorados, que são extremamente nocivos ao meio ambiente (WONG et al., 2001).

Com base no que foi abordado anteriormente, o objetivo geral deste trabalho foi a otimização da produção da enzima celulase em fermentação em estado sólido por Penicillium $s p$., empregando substrato agroindustrial de casca de soja, variando as concentrações de esporos e a umidade do substrato, usando planejamento estatístico de experimentos. 


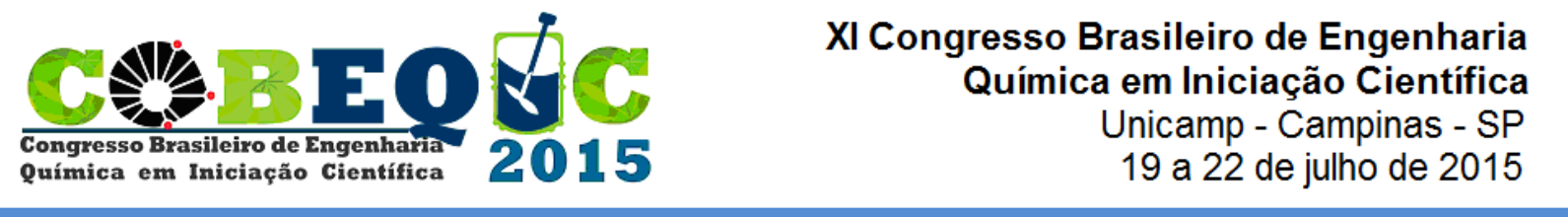

\section{METODOLOGIA}

\subsection{Produção de xilanase}

A produção da enzima xilanase foi realizada através do crescimento do fungo identificado como Penicillium sp. em $10 \mathrm{~g}$ de substrato de casca de soja, com a umidade regulada no substrato com variações de $34 \mathrm{U} \%$, 40U\%, 55U\%, $70 \mathrm{U} \%$ e $76 \mathrm{U} \%$ e variações de concentração de esporos 4,6Log, $5 \mathrm{Log}, 6 \mathrm{Log}, 7 \mathrm{Log}$ e 7,4Log. A germinadora se manteve com umidade $100 \%$ e temperatura de $30^{\circ} \mathrm{C}$.

\subsubsection{Substrato Agroindustrial}

O resíduo agroindustrial utilizado foi a casca de soja cedida Empresa Olfar, Erechim/RS.

\subsubsection{Efeito da concentração de esporos}

Para avaliar se a quantidade de esporos apresentava algum efeito na produção de enzima celulase foram realizados estudos em diferentes concentrações de esporos de Penicillium sp. de $4 \times 10^{4}, 1 \times 10^{5}, 1 \times 10^{6}, 1 \times 10^{7}$ e $2,5 \times 10^{7}$ esporos por grama de meio úmido e tempos de bioprodução de 7 e 14 dias, respectivamente.

O teor de umidade é um fator determinante no crescimento dos micro-organismos, portanto foi analisada a influência do teor de umidade na produção enzimática de celulase em diferentes tempos de bioprodução ( 7 e 14 dias). No meio de bioprodução composto por casca de soja foi ajustada a umidade a 34, 40, 55, 70 e $76 \%$ (b.u.). A quantidade volumétrica de água a ser adicionada foi dimensionada através de cálculo de balanço de massa, descontando a umidade inicial da mistura e a alíquota de suspensão de esporos.

Como estratégia foi realizado um planejamento fatorial completo $2^{2}$ (Delineamento Central Composto Rotacional - DCCR), incluindo 4 ensaios fatoriais, 4 ensaios nos pontos axiais e 3 repetições no ponto central, totalizando 11 ensaios. As variáveis independentes foram: concentração de esporos $\left(\mathrm{X}_{1}\right)$, e umidade $\left(\mathrm{X}_{2}\right)$. A Tabela 1 apresenta as variáveis independentes e seus respectivos níveis. A variável dependente (resposta) foi a medida da atividade residual $(\mathrm{U} / \mathrm{g})$, Xilanase.

Tabela 1: Variáveis independentes e níveis utilizados no planejamento fatorial completo $2^{2}$ para a produção de celulase.

\begin{tabular}{lcccccc}
\hline \multirow{2}{*}{$\begin{array}{c}\text { Variáveis } \\
\text { Independentes }\end{array}$} & Códigos & \multicolumn{5}{c}{ Níveis } \\
\cline { 3 - 7 } & & $\mathbf{- 1 , 4 1}$ & $\mathbf{- 1}$ & $\mathbf{0}$ & $+\mathbf{1}$ & $\mathbf{+ 1 , 4 1}$ \\
\hline [ ] esporos (Log) & $\mathrm{X}_{1}$ & 4,6 & 5 & 6 & 7 & 7,4 \\
Umidade (\%) & $\mathrm{X}_{2}$ & 34 & 40 & 55 & 70 & 76 \\
\hline
\end{tabular}

* Triplicata do ponto central 


\subsubsection{Extração Enzimática}

Após cada tempo de fermentação ( 7 e 14 dias) $10 \mathrm{~g}$ de meio fermentado foi transferido para elernmeyer de $250 \mathrm{~mL}$ e diluído em solução de citrato de sódio $0,2 \mathrm{M}$ pH 4,9 na razão 1:15 ( $3,33 \mathrm{~g}$ de substrato fermentado para $50 \mathrm{~mL}$ de tampão). Os frascos foram colocados em um agitador orbital mecânico (Nova Ética, incubadora $430 \mathrm{RDB}$ ) por 30 minutos a $50^{\circ} \mathrm{C}$ e $100 \mathrm{rpm}$.

\subsubsection{Determinação da atividade de Xilanase}

Técnicas para medir a atividade de celulase total são necessárias para comparar a eficácia da atividade da celulase entre micro-organismos ou suas enzimas secretadas. A atividade de xilanase foi determinada pela quantidade de açúcares redutores liberados a partir de xilana "birchwood" (Sigma), conforme descrito por BAILEY et al. (1992). Os acúcares redutores (como a D-xilose) foram dosados espectrofotometricamente, pelo método do DNS (MILLER, 1959), envolvendo quatro categorias de reações: tubos das amostras a serem quantificadas (atividade enzimática); tubo do branco reacional (para zerar o espectrofotômetro) e tubos controle da enzima (enzima e/ou extrato enzimático sem substrato).

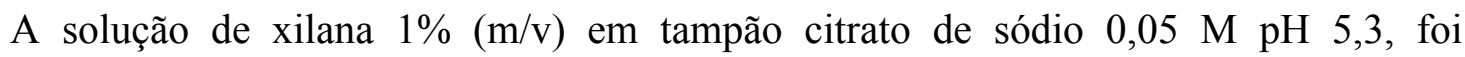
previamente aquecida, adicionando-se $1,8 \mathrm{~mL}$ da solução em tubos que são incubados em banho termostatizado, a $50{ }^{\circ} \mathrm{C}$ por 5 minutos. Em seguida, acrescentou-se $200 \mu \mathrm{L}$ da enzima e/ou extrato enzimático, incubando-se a mistura por 5 minutos. Desta, retirou-se $0,5 \mathrm{~mL}$, que foram adicionados a $0,5 \mathrm{~mL}$ de DNS. Esta reação foi conduzida em banho de água fervente por 5 minutos, sendo paralisada com o resfriamento da solução em banho de gelo. Após a adição de $8 \mathrm{~mL}$ da solução tartarato de sódio e potássio, a absorbância das amostras foram lidas em espectrofotômetro a $540 \mathrm{~nm}$, contra um branco reacional.

\subsubsection{Análise estatística}

Os resultados foram tratados estatisticamente pela Análise de Variância (ANOVA) e a comparação entre as diferenças das médias, com o Software Statistica versão 8.0, a nível de significância de $95 \%$.

\section{RESULTADOS E DISCUSSÃO}

Para a Xilanase com 7 dias de fermentação a máxima atividade foi de 215,08 U/g (Ensaio 9, Tabela 2), onde o meio de cultivo apresentava as concentrações de $10 \mathrm{~g}$ de casca de soja com a concentração de esporos igual a $6 \log$ e umidade igual a $55 \%$. Já para a Xilanase com 14 dias de fermentação a máxima atividade foi de 435,35U/g (Ensaio 4, Tabela 2), onde o meio de cultivo apresentava as concentrações de $10 \mathrm{~g}$ de casca de soja com a concentração de esporos igual a 7 Log e umidade igual a $70 \%$. 
Tabela 2: Matriz do planejamento fatorial completo $2^{2}$ valores reais e codificados e respostas em determinação da atividade de Xilanase.

\begin{tabular}{ccccc}
\hline & $\begin{array}{c}\boldsymbol{X 1} \\
\text { (conc. de esporos) }\end{array}$ & $\begin{array}{c}\boldsymbol{X} \mathbf{(} \%) \\
\text { Xilanase (U/g) } \\
\mathbf{7 ~ d i a s}\end{array}$ & $\begin{array}{c}\text { Xilanase (U/g) } \\
\mathbf{1 4} \text { dias }\end{array}$ \\
\hline $\mathbf{1}$ & $-1\left(1.10^{5}\right)$ & $-1(40)$ & 75,70 & 36,76 \\
$\mathbf{2}$ & $1\left(1.10^{7}\right)$ & $-1(40)$ & 50,00 & 35,48 \\
$\mathbf{3}$ & $-1\left(1.10^{5}\right)$ & $1(70)$ & 179,79 & 416,58 \\
$\mathbf{4}$ & $1\left(1.10^{7}\right)$ & $1(70)$ & 179,00 & 435,35 \\
$\mathbf{5}$ & $-1,41\left(4.10^{4}\right)$ & $0(55)$ & 155,28 & 128,97 \\
$\mathbf{6}$ & $1,41\left(2,5.10^{7}\right)$ & $0(55)$ & 178,58 & 220,86 \\
$\mathbf{7}$ & $0\left(1.10^{6}\right)$ & $-1,41(34)$ & 33,73 & 21,62 \\
$\mathbf{8}$ & $0\left(1.10^{6}\right)$ & $1,41(76)$ & 187,00 & 220,00 \\
$\mathbf{9}$ & $0\left(1.10^{6}\right)$ & $0(55)$ & 215,08 & 210,00 \\
$\mathbf{1 0}$ & $0\left(1.10^{6}\right)$ & $0(55)$ & 200,00 & 224,42 \\
$\mathbf{1 1}$ & $0\left(1.10^{6}\right)$ & $0(55)$ & 215,00 & 222,02 \\
\hline
\end{tabular}

$\mathrm{X}_{1}=$ concentração de esporos $(\mathrm{Log}) ; \mathrm{X}_{2}=$ umidade $(\%)$. Variáveis independentes fixas: $30^{\circ} \mathrm{C}$.

A Equação 1 apresenta o modelo codificado de segunda ordem que descreve a atividade da xilanase em função da concentração de esporos e umidade, dentro das faixas estudadas. $\mathrm{O}$ modelo foi validado pela análise de variância, com um coeficiente de correlação de 0,98 e $\mathrm{F}$ calculado 17,74 vezes maiores que o valor do $\mathrm{F}$ tabelado. Os quais permitiram a construção de superfícies de resposta e curvas de contorno apresentadas na Figura 1 demonstrando que a máxima produção de Xilanase em 7 dias se dará com concentração de $6 \log$ e $55 \%$ de umidade, referente ao ensaio 9.

Xilanase $=210,00-26,01 \cdot X_{1}^{2}+56 \cdot 31 \cdot X_{2}-54,47 \cdot X_{2}^{2}$

Onde, Xilanase $=$ Atividade de Xilanase $(\mathrm{U} / \mathrm{g}) ; \mathrm{X}_{1}=$ Concentração de esporos $(\mathrm{Log}), \mathrm{X}_{2}=$ Umidade (\%). 
Figura 01: Superfícies de resposta e curvas de contorno em função da concentração de esporos e umidade para bioprodução de Xilanase (U/g).
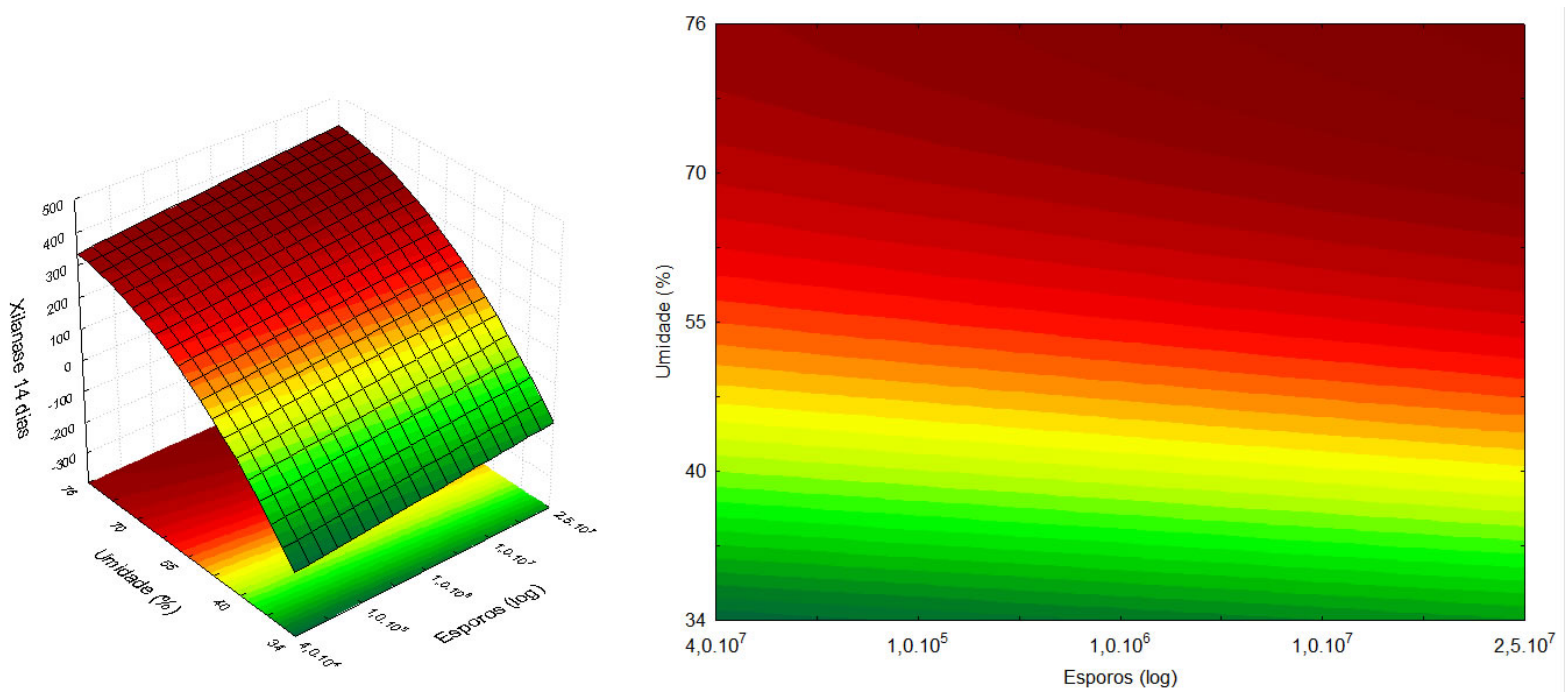

A Equação 2 apresenta o modelo codificado de segunda ordem que descreve a atividade da Xilanase de 14 dias em função da concentração de esporos e umidade, dentro das faixas estudadas. O modelo foi validado pela análise de variância, com um coeficiente de correlação de 0,87 e $\mathrm{F}$ calculado 1,81 vezes maiores que o valor do $\mathrm{F}$ tabelado. Os quais permitiram a construção de superfícies de resposta e curvas de contorno apresentadas na Figura 02 demonstrando que a máxima produção de Xilanase em 14 dias se dará com concentração de $7 \log$ e $70 \%$ de umidade, referente ao ensaio 4.

Xilanase $=218,48+18,44 . \mathrm{X}_{1}+132,82 \cdot \mathrm{X}_{2}-28,10 \cdot \mathrm{X}_{2}^{2}$

Onde, Xilanase $=$ Atividade de Xilanase $(\mathrm{U} / \mathrm{g}) ; \mathrm{X}_{1}=$ Concentração de esporos $(\mathrm{Log}), \mathrm{X}_{2}=$ Umidade (\%).

Figura 02: Superfícies de resposta e curvas de contorno em função da concentração de esporos e umidade para bioprodução de Xilanase (U/g).
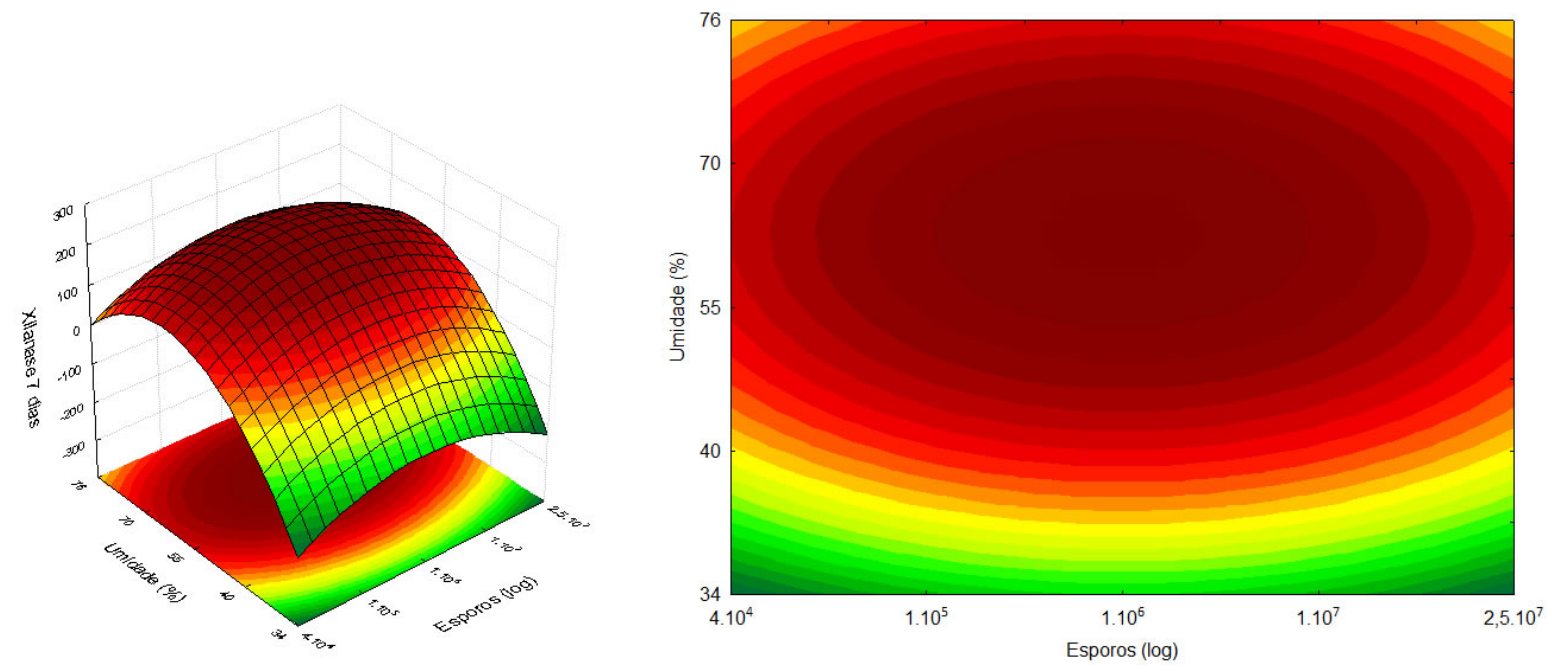


\section{CONCLUSÃO}

Neste trabalho observou-se que a concentração de esporos não apresenta diferença significativa quando comparado no mesmo tempo de fermentação, porém pôde-se observar queo teor de umidade são variáveis importantes na produção da enzima FPase. O melhor rendimento foi verificado quando utilizado casca de soja a uma concentração de esporos de $5 \times 10^{5} / 10$ gramas de bioproduto no tempo de 7 dias $(1,19 \mathrm{U} / \mathrm{g})$ e o teor de umidade de $70 \%$, quando comparado ao tempo de 14 dias $(0,94 \mathrm{U} / \mathrm{g})$ no valor da atividade enzimática. Portanto, o sucesso da produção comercial de enzimas depende dos parâmetros de processo, visando à minimização dos custos do meio de cultura utilizado na fermentação.

\section{AGRADECIMENTOS} financeiro.

Os autores agradecem a Uri Erechim, FAPERGS, CAPES e CNPq pelo apoio

\section{REFERÊNCIAS}

BAILEY, M. J.; BIELY, P.; POUTANEN, K. Interlaboratory testing of methods for assay of xylanase activity. Journal of Biotechnology, vol. 23, p. 257-270, 1992.

LEE, J. W.; PARK, J. Y.; KWON, M.; CHOI, I. G. Purification and characterization of a thermostable xilanase from the brown-rot fungus Laetiporus sulphureus. Journal of Bioscience and Bioengineering. v. 107, n. 1, p. 33-37, 2009.

MILLER, G. L., Use of dinitrosalisylic acid reagent for determination of reducin sugar. Analytical Chemistry, v.31, p. 426 - 428, 1959.

WONG, K. K. Y.; ALISON, R. W.; SPEHR, S., Effects of alkali and oxygen extractions of kraft pulp on xylanase-aided bleaching. Journal of Pulp and Paper Science, v. 27, p. 229-234, 2001.

ZANOELO, F. F.; POLIZELI, M. L. T. M.; TERENZI, H. F.; JORGE, J. A. Purification and biochemical properties of a thermostable xylose-tolerant $\beta$-D-xylosidase form Scytalidium thermophilum. Journal of Industrial Microbiology and Biotechnology, v. 31, p. 170-176, 2004. 